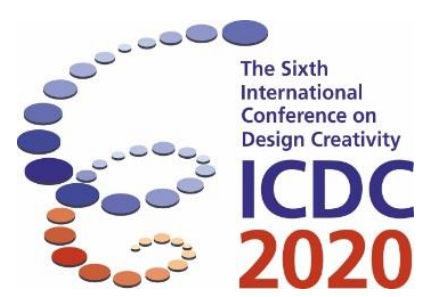

\title{
An Interaction-based Design Thinking Approach for Architecture as A Complex Adaptive System
}

\author{
Tao Shen ${ }^{1}$ and Yukari Nagai ${ }^{2}$ \\ ${ }^{1}$ College of Design and Innovation, Tongji University, Shanghai, China \\ ${ }^{2}$ Knowledge Science, Japan Advanced Institute of Science and Technology, Nomi City, Japan
}

\begin{abstract}
Creativity is a vital part of design studies, and many literatures have approached design creativity from the perspectives of cognition and social behaviors. Several methods and tools have been introduced for enhancing design creativity, most of which focus on two aspects - the process and outcome of design. However, these methods for creative architecture design mainly follow a reductionist approach, and the complex nature of the 21 st century architecture is often ignored. In this paper, we first review the simplicity and complexity of architecture, based on which we acknowledge architecture as a complex adaptive system, and present a new design thinking approach for creative architecture design, named "Concept Topology Optimization" (CTO). A case study that utilizes CTO is conducted to explore the application of the proposed method in the architecture space design, and a controlled experiment demonstrates the effectiveness of this method by measuring the idea quality and quantity.
\end{abstract}

Keywords: creativity, architecture design, complexity science, topology

\section{Introduction}

The need for proactive methods of creative conception and strategizing has been emphasized by numerous researchers. Meanwhile, the design process of contemporary architecture has become more complex because of the increase in the number of design projects and stakeholders (Kiatake \& Petreche, 2012). Lawson (2012) stated that, in the most general sense, we can view problem solving as a very basic human activity and design as a type of problem solving. Problems can be classified into welldefined (well-structured) and ill-defined (wicked) problems (Schacter, Gilbert \& Wegner, 2009; Cross, 2000). Well-defined problems are those that have clearly defined goals, such as a chess game or math problems (Cross, 2000), whereas, ill-defined problems do not have clearly defined goals nor a clear solution path. Rittel \& Webber (1973) contended the idea of ill-defined problems; they argued that the problems that socialists or designers dealt with were different from the problems faced by scientists or engineers, and that these problems were ill-defined problems. Therefore, architecture design could be considered an ill-defined (wicked) problem, which increased the complexity of architecture.

As the world moves toward integration, knowledge is becoming increasingly specialized. The root cause of this phenomenon is that, ever since the evolution of scientific development from ancient visual speculation to modern experimental analyses, the traditional academic research route has been based on the hypothesis of reductionism (Putnam, 1973). In this context, each phenomenon in the real world can be regarded as a collection of lower level, basic phenomena; thus, the laws of low-level motion 
forms can replace the laws of advanced motion forms. Therefore, by continually subdividing research, researchers can finally understand the advanced laws. As a result, disciplines are becoming increasingly detailed and the number of specialized knowledge outputs is increasing. The gaps among various disciplines are growing and people are often unable to obtain a clear overview. This type of separation weakens communication among the various disciplines. For example, each of the fields of biology, psychology, medicine, and sociology define humans as different objects of knowledge. Although all these different definitions refer to the same object, the concepts of each are almost incommensurable. Since the middle of the 20th century, people have shown intense interest in complexity and complex systems. A wave of interest following the First World War led to the birth of the term "Holism", which led to the concepts of "Gestalt" and "Creative Evolution". A second round of interest after the Second World War coined the hot terms of "Information", "Feedback", "Cybernetics", and "General System". In the present day, the words often associated with complexity are "Chaos", "Adaptive Systems", "Genetic Algorithms", and "Cellular Automata". Although reductionism still plays an important role, the theoretical paradigm has quietly shifted from reductionism to complexity.

In this paper, we aim to acknowledge architecture as a complex adaptive system (CAS). On this basis, we further propose an interaction-based design thinking approach termed "Concept Topology Optimization" (CTO) for effective architecture design on large and complex scales.

\section{Related literature}

\subsection{Simplicity and complexity of architecture}

Modern architecture pursues simplicity in both faith and specific practical strategies. The world that modernists dream of is objective, regular, predictive, and controllable (Frampton \& Futagawa, 1983). However, this view of the world (a presupposition of the world view) is unrealistic and utopian, in the contemporary sense. In the process of continuous simplification, it is easy to lose the quality that should be possessed in the whole. With the aging of the first generation of modernist architects, many architects have realized that modernist architecture is highly selective in deciding which problems to solve. It ignores many aspects of architecture (Klotz \& Donnell, 1988), and often fails to figure out more complex problems (Frampton, 2015).

That is, the recognition of modern architecture is also the premise and hypothesis of defining the problem "the complex world is compounded by simple things". However, after the epoch-making work on "Complexity and Contradiction in Architecture" by Robert Venturi (1977), the architectural trend could no longer return to pure modernism but moves in the more and more complex direction.

\subsection{Architecture as a complex adaptive system}

The complex adaptive system (CAS) theory, an important branch of complexity theory, is the sublimation and crystallization of the complexity theory. Ever since its introduction by Holland in 1994, CAS has attracted widespread attention in the academic community, and has been widely used in economic, eco, and social systems. Holland (1995) summarized seven points as the necessary and sufficient conditions for a CAS, which included four characteristics (aggregation, nonlinearity, flow, and diversity) and three mechanisms (identification, internal models, and building blocks). Each CAS satisfies these seven basic characteristics, and any complex system that satisfies these seven basic characteristics can be defined as CAS (Holland \& Wolf, 1998). Table 1 presents the basic characteristics of architecture, in the context of the seven basic characteristics. These characteristics demonstrate that architecture can be considered a CAS.

\subsection{Viewing architecture as CAS}

As mentioned above, we argue that architecture is best construed as CAS. This system is radically different from the static system of architecture, as it involves the following features:

1. Architecture as CAS consists of multiple agents, which interact with each other.

2. Architecture as CAS is adaptive. The architecture design is conducted upon the background of simultaneous past, present, and future interactions. 
3. Architecture is the consequence of competing factors, ranging from the architect's personal experience to social motivations.

4. The structures of architecture emerge from art, culture, policy, economics, humanity, functionality, techniques, and environment.

Table 1. Basic characteristics of architecture as a complex adaptive system

\begin{tabular}{|c|c|}
\hline Characteristic & Content \\
\hline Aggregation & $\begin{array}{l}\text { The formation and development of architecture depend on the gathering of people. From } \\
\text { the early settlements to small towns, the direct driving force for the generation and } \\
\text { development of architecture has been the spatial agglomeration effect of human beings. } \\
\text { The gathering of people produces new architectural functions, industrial aggregation } \\
\text { brings huge-scale effects, and so on. These are the aggregation characteristics of } \\
\text { architecture (Roth, 2018). }\end{array}$ \\
\hline Nonlinearity & $\begin{array}{l}\text { Nonlinearity claims that the whole is greater than the sum of its parts. While exploring } \\
\text { the nature of architecture, scholars discovered the weakness of reductionism in solving } \\
\text { complex architecture problems; the traditional linear thinking does not apply to complex } \\
\text { architecture systems. The nonlinear and complex nature of architecture is being } \\
\text { increasingly recognized (Jiang \& Adeli, 2008). }\end{array}$ \\
\hline Flow & $\begin{array}{l}\text { The essence of flow is the exchange of matter, energy, and information among subjects. } \\
\text { Research on spatial forms such as capital flow, logistics, people flow, and information } \\
\text { flow has captured much attention. An important characteristic of flow is its circulating } \\
\text { effect, which is easy to understand from the perspective of people flow in architecture. } \\
\text { The circulating flow of people is a dynamic architecture space system. This also provides } \\
\text { a new theoretical basis for us to build green architecture (Pallasmaa, J, 2007). }\end{array}$ \\
\hline Diversity & $\begin{array}{l}\text { Diversity can be observed everywhere in architecture systems. From a microperspective, } \\
\text { architecture contains various functions, different organizational structures, etc. From a } \\
\text { macroperspective, each architecture has its own characteristics to constitute a reasonable } \\
\text { architecture system (Ubarretxena Belandia \& Engelman, 2001). }\end{array}$ \\
\hline Identification & $\begin{array}{l}\text { Identification is the basis of interaction. From the microscopic point of view, coordination } \\
\text { between different architecture spaces relies on identifying different functions. From the } \\
\text { macroperspective, the architecture function area division is also based on the } \\
\text { identification of architecture's resources. }\end{array}$ \\
\hline Internal Models & $\begin{array}{l}\text { The "collage architecture" theory (Johnson, 1994) holds that architecture design has not } \\
\text { been carried out on a piece of white paper, but on the background of architecture produced } \\
\text { by historical memory and progressive architecture accumulation. This is architecture's } \\
\text { process of development, learning from past experiences, and decision making for the } \\
\text { future. The study of the internal model of architecture will contribute to the development } \\
\text { of architecture. }\end{array}$ \\
\hline Building Blocks & $\begin{array}{l}\text { Building blocks are the basic components of the architecture internal model. The diversity } \\
\text { of internal models comes from various combinations of building blocks. This is similar to } \\
\text { the different development modes of architecture in different stages. Some architecture can } \\
\text { skip some stages to form a leap-forward development; this is caused by different } \\
\text { combinations of architecture blocks (Frazer, 1995). }\end{array}$ \\
\hline
\end{tabular}

Consequently, the advantage of viewing architecture as CAS is that it provides us with a unified account of seemingly unrelated architecture phenomena. Moreover, it is believed that the development of architecture is a process of adaptive evolution (Holland, 1995, 1998; Holland, Gong, Minett, Ke, \& Wang, 2005). To be more specific, architecture as CAS involves multiple agents interacting with each other, which provides the ability of self-regulation according to environmental changes. These agents adapt to the environment (including the natural environment and human environment) in order to develop themselves, which is a commonality of adaptation. On the other hand, the adapting process adapts the agents' responses to changes in environmental conditions. With different agents and different environmental conditions, the degree and process of adaptation also change, which is the diversity of adaptation (Giacomoni, Kanta, Zechman, 2013). 
In short, we have understood the commonality and diversity of agents' adaptation in architecture as CAS; however, how to utilize the characteristics in architecture remains a question. In this research, we propose a new design thinking approach to provide an answer to this question, which is named "Concept Topology Optimization” design thinking approach.

\section{Design thinking approach: "Concept Topology Optimization"}

\subsection{Content of Topology}

As mentioned above, architecture as CAS is adaptive, and consists of multiple agents interacting with each other, which leads to complex architecture characteristics. On the other hand, it is believed that there is no complex system that is too complicated to touch. Humans are accustomed to facing complex systems and overcoming complex problems. Complex systems may arise from a very simple nonlinear equation or a simple set of rules (Corrado, 2019). For example, the Mandelbrot Set has amazing levels of complexity; however, it arises from extremely simple mathematics: $\mathrm{f}(\mathrm{z})=\mathrm{Z} 2+\mathrm{C}$. Topology is a discipline that studies the invariant properties of geometry or space after continuous change (Munkres, 2014). This is the main reason why we developed topology as a concept optimizing process and presented the "Concept Topology Optimization" for architecture design as CAS, in this paper.

\subsection{Concept Topology Optimization for Architecture as A Complex Adaptive System}

Prior design creativity studies have shown that new design concepts arise from the analogy (Weisberg, 2006; Linsey et al., 2012), synthesis, blending (Taura and Nagai, 2012), or other general forms of the creative transformation of existing knowledge or concepts. Recently, Youn et al. (2015) presented empirical evidence, from patent analysis, that modern inventions primarily arose from a combination of existing technologies rather than from the introduction of new technologies. In this thesis, we classify these methods for creative design as "Concept Linear Optimizations", they are easy to understand and are useful in relatively simple design tasks. However, for architecture as CAS, these methods may not be the most suitable optimal solutions.

In this research, we define Concept Topology Optimization (CTO) is an interaction-based design thinking approach that optimizes design concept with a given ground structure or mixed ground structures, for maximizing the performance of architecture as CAS. Figure 1 shows the basic model of CTO.

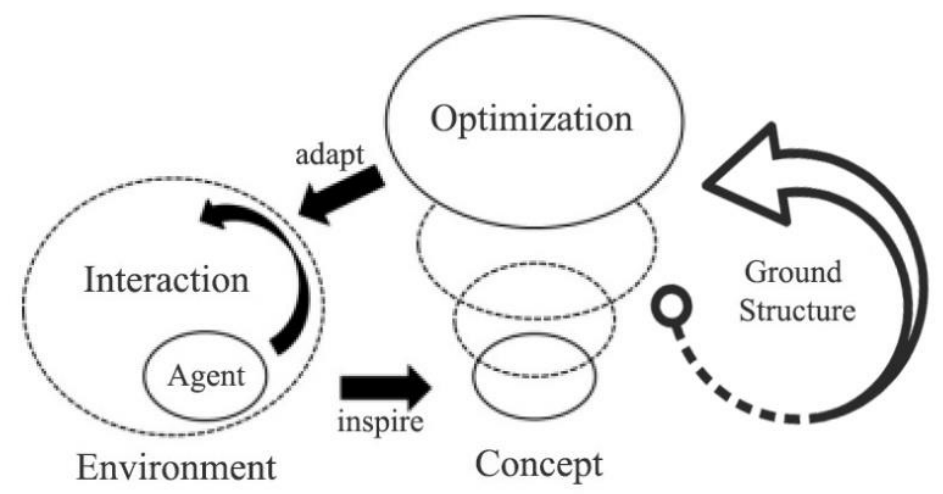

Figure 1. Basic model of concept topology optimization

An 'Design Agent' is an actor that has the capacity to adapt to their state to some change within their environment. As an analogy to the application of topology in architecture form design, we suppose 'Topology Optimization' can also be divided into three levels in CTO:

1. Differential Homomorphic CTO: Optimization does not change the original concept but requires the ability of abstraction and review. 
2. Homomorphic CTO: On this level, optimization includes analogy, synthesis, blending or more general forms of creative transformation of existing knowledge or concepts. After the topology optimization, the changing inheritance relationship can still be found in the new concept and the logic process of the concept optimization can be clearly seen. (Case study is an example)

3. Non-homeomorphic CTO: This level is accompanied by the tearing, cutting, and blocking on the deformation of the second level. This optimization destroys the overall structure of the original concept to some extent, belongs to the scope of emergence.

\section{Case study: Explore human-centered architecture space design method by using CTO design thinking approach}

\subsection{Traditional architecture space design method}

Traditional method in architecture space design includes the following four steps (Ching, 2014):

Step 1: Collect numerous requirements from the client and user.

Step 2: Build the brief to response to the requirements in step 1.

Step 3: Consider spatial relationships.

Step 4: Create the solution.

The traditional architecture space design method is a linear problem-solving design process (British Design Council, 2015). However, Innovation should not be seen as a linear process, it should be a feedback loop - 'Build, Measure, Learn' (Ries, 2011) focused on swiftly improving the existing solution. In addition, this case study link human with architecture as a changing environment, thus the new method for architecture space design is a human-centred design method, in which the key principle is that designers 'empathize with the end user' (Kelley and Kelley, 2013).

\subsection{Human-centered architecture space design method}

Research on novel methods in the architectural design process can enhance design researches. Structured design methods can make the design process more organized and learnable; thus we use substance-field (Su-field) (Mao \& Zhang, 2007) as the ground structure in this case study. Su-field analysis is a TRIZ analytical tool for modeling problems related to existing technological systems. This case study aims to explore a new method for more creative human-centered architecture space design, based on Su-field analysis, using the proposed CTO design thinking approach. Figure 2 shows the model of CTO used in this case. In this method, human is the design agent. The "Field" for human is the environment and the Su-field model is the ground structure (Shen, Nagai, \& Kim, 2019).

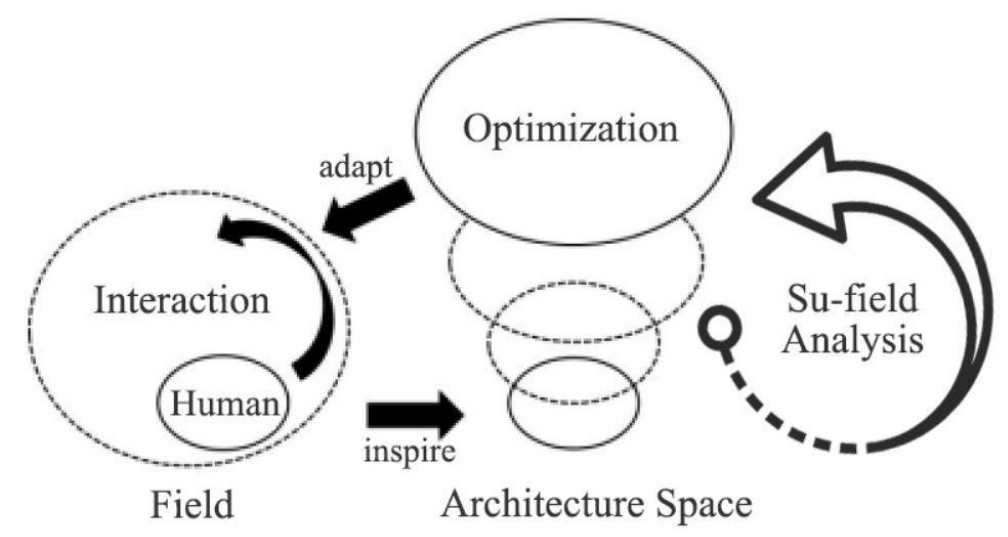

Figure 2. Model of concept topology optimization in case study

In this method, the effect of architecture space could be on human from the output of the field, the term field is used in the broadest sense, including the fields of physics and psychology. A complete architecture space model is a triad of human, spatial elements and the field which is shown in Figure 3. 


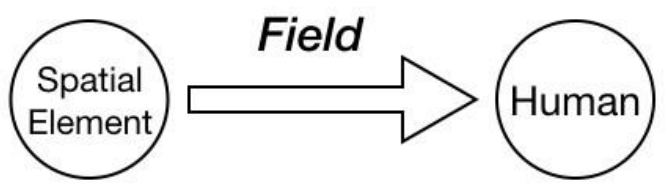

Figure 3. A Complete architecture space model

The innovative problem is modelled to show the relationships among spatial elements, human and the field. Complex systems can be modelled by multiple, connected Su-field Models.

There are four steps to follow in making the Su-field Model:

1. Identify the spatial elements.

2. Construct the model. After completing these two steps, stop to assess the completeness and effectiveness of the system. If some element is missing, try to identify what it is or find the substitute.

3. Consider design solutions from the general solutions.

4. Develop a concept to support the solution. In following Steps 3 and 4, activity shifts to other knowledge-based tools.

\subsection{Data collection and analysis}

In this study, we used a control experiment to demonstrate the effectiveness of the proposed method by measuring the idea quality and quantity. In this experiment, the participants were 16 students pursuing the Bachelor of Architecture degree in the same university. All of them had completed the basic architecture course and received credits.

In this study, we adopted the method presented by Shah et al. (2003). In this method, the idea quality could be estimated sufficiently well even if the quantitative information was not sufficient to perform a formal analysis in the concept stage. In addition, this method added all the quality scores for all the alternatives to achieve the total score for the set. As a result, the idea quality was defined as:

$$
M=\sum_{j=1}^{m} f_{j} \sum_{k=1}^{2} S_{j k} p_{k} / n * \sum_{j=1}^{m} f_{j}
$$

In this equation, $S_{j k}$ is the score for the quality of function $j$ at stage $k ; m$ is the total number of functions; $f j$ is the weight of function $j$; and $p_{k}$ is the weight for stage $k$. The denominator is for normalizing to a scale of 10 .

\subsection{Experiment process}

The 16 participants were divided into two groups - Group A and Group B. They were all asked to design a play space for children under 12 years, within an hour. The difference was that Group A was trained to use the new method in the design process, whereas, Group B completed the design task using the traditional method.

\subsection{Experiment results}

The design ideas were collected from the 16 participants. Table 2 shows an evaluation of the quality and quantity of the ideas.

We analyzed these data using an unpaired Samples T-test, the results of which are presented in Table 3.

The results of both idea quality and quantity were significant, and indicated that the architecture space design method using the CTO approach was an effective tool for architecture design as it had the ability to improve both the idea quality and quantity of the participants. 
Table 2. Idea quality and quantity of each participant

\begin{tabular}{|c|c|c|c|c|c|}
\hline Group A & $\begin{array}{c}\text { Idea } \\
\text { Quality }\end{array}$ & $\begin{array}{c}\text { Idea } \\
\text { Quantity }\end{array}$ & Group B & $\begin{array}{c}\text { Idea } \\
\text { Quality }\end{array}$ & $\begin{array}{c}\text { Idea } \\
\text { Quantity }\end{array}$ \\
\hline A1 & 6.15 & 3 & B1 & 4.14 & 2 \\
\hline $\mathbf{A 2}$ & 5.64 & 2 & B2 & 3.56 & 3 \\
\hline $\mathbf{A 3}$ & 4.96 & 4 & $\mathbf{B 3}$ & 4.07 & 2 \\
\hline $\mathbf{A 4}$ & 6.54 & 3 & $\mathbf{B 4}$ & 4.21 & 1 \\
\hline $\mathbf{A 5}$ & 5.46 & 4 & $\mathbf{B 5}$ & 5.13 & 3 \\
\hline $\mathbf{A 6}$ & 4.87 & 3 & $\mathbf{B 6}$ & 3.76 & 2 \\
\hline $\mathbf{A 7}$ & 5.12 & 6 & $\mathbf{B 7}$ & 4.28 & 2 \\
\hline $\mathbf{A 8}$ & 5.98 & 4 & $\mathbf{B 8}$ & 5.76 & 3 \\
\hline
\end{tabular}

Table 3. Results of unpaired sample T-test

\begin{tabular}{|c|c|c|c|c|c|c|}
\hline Group & $\begin{array}{c}\text { Idea } \\
\text { Quality } \\
\overline{\mathbf{X}}\end{array}$ & $\begin{array}{c}\text { Idea } \\
\text { Quality } \\
\text { SD }\end{array}$ & Sig & $\begin{array}{c}\text { Idea } \\
\text { Quantity } \overline{\mathrm{X}}\end{array}$ & $\begin{array}{c}\text { Idea } \\
\text { Quantity SD }\end{array}$ & Sig \\
\hline $\mathbf{A}$ & 5.59 & 0.60 & \multirow{2}{*}{$\begin{array}{c}0.04 \\
<0.05\end{array}$} & 3.63 & 1.19 & \multirow{2}{*}{$\begin{array}{l}0.028 \\
<0.05\end{array}$} \\
\hline B & 4.36 & 0.73 & & 2.25 & 0.71 & \\
\hline
\end{tabular}

\section{Discussion}

We developed an architecture space design method based on the CTO design thinking approach. The case study suggested that the CTO design thinking approach had the ability to guide designers to figure out situations based on the design agents' interactions with the environment. In addition, the CTO design thinking approach empowered designers to utilize verified theories or tools as "ground structures" to conduct concept optimization. As a result, the first point could help designers find the "Right" situation and the second point could stimulate the designers' persistence to find the "Best" solution.

Furthermore, the CTO design thinking approach attempted to support designers in "making knowledge productive" and considered the ways of complexity science. The case study suggested that the CTO design thinking approach could stimulate effective and creative architecture design. Moving forward, such a hypothesis must be tested further with more experimental data.

\section{Conclusion}

In this thesis, "Concept Topology Optimization" was introduced into architecture as CAS. It could break the static and certain architectural design thinking approach and open up new directions for architecture design. CTO could be considered a dynamic, continuous, and changing design thinking approach. However, we still have limited understanding of the influences of many factors on the effectiveness of CTO. In future research, human experiments will be necessary to explore the potential factors that condition the effectiveness of CTO.

\section{References}

British Design Council (2015). "The design process: what is the Double Diamond?"

Corrado, A. J. (2019). Dynamics of complex systems. CRC Press.

Cross, Nigel. (2000). Engineering design methods: strategies for product design (Vol. 58): Wiley Chichester.

Frampton, K. (2015). A Genealogy of modern Architecture. Comparative Critical Analysis of Built Form.

Frampton, K., \& Futagawa, Y. (1983). Modern architecture. ADA Edita.

Frazer, J. (1995). An evolutionary architecture.

Giacomoni M H, Kanta L, Zechman E M. (2013) Complex adaptive systems approach to simulate the sustainability of water resources and urbanization. Journal of Water Resources Planning and Management, 139(5). 554-564.

Holland, J. H. (1995). Hidden order: How adaption builds complexity. Reading, MA: Addison-Wesley 
Holland, J. H., \& Wolf, S. (1998). Hidden order. Integrative Physiological and Behavioral Science, 33(1), 72-72. Holland, J. H., Gong, T., Minett, J. W., Ke, J., \&Wang, W. S.-Y. (2005). Language acquisition as a complex adaptive system. In J. W. Minett \&W. S.-Y. Wang (Eds.), Language acquisition, change and emergence (pp. 411435). Hong Kong: City University ofHong Kong Press.

Jiang, X., \& Adeli, H. (2008). Dynamic fuzzy wavelet neuroemulator for non-linear control of irregular building structures. International Journal for Numerical Methods in Engineering, 74(7), 1045-1066.

Johnson, P. A. (1994). The Theory of Architecture: Concepts Themes \& Practices. John Wiley \& Sons.

Kelley, D. and Kelley, T. (2013). Creative confidence: unleashing the creative potential within us all. London, United Kingdom: William Collins.

Kiatake, M., \& Petreche, J. R. D. (2012). A case study on the application of the theory of inventive problemsolving in architecture. Architectural Engineering and Design Management, 8(2), 90-102.

Klotz, H., \& Donnell, R. (1988). The history of postmodern architecture. Cambridge, MA: Mit Press.

Lawson Munkres, J. (2014). Topology. Pearson Education.

Lawson, B. (2012). What Designers Know: Taylor \& Francis.

Linsey, J., Markman, A., and Wood, K. (2012). Design by analogy: a study of the WordTree method for problem re-representation. Journal of Mechanical Design, 134(4), 041009.

Mao, X., \& Zhang, X. (2007). Generalized solutions for Su-Field analysis. TRIZ Journal.

Pallasmaa, J. (2007). The architecture of image. Rakennustieto.

Putnam, Hilary. "Reductionism and the nature of psychology." Cognition (1973).

Ries, E. (2011). The Lean Startup: how today's entrepreneurs use continuous innovation to create radically successful businesses. New York: Crown Business.

Rittel, Horst W. J., \& Webber, Melvin M. (1973). Dilemmas in a general theory of planning. Policy sciences, 4(2), 155-169.

Roth, L. M. (2018). Understanding architecture: Its elements, history, and meaning. Routledge.

Schacter, Daniel L., Gilbert, Daniel T., \& Wegner, Daniel M. (2009). Introducing psychology: Worth Publishers. Shah, J. J., Smith, S. M., \& Vargas-Hernandez, N. (2003). Metrics for measuring ideation effectiveness. Design studies, 24(2), 111-134.

Shen, T., Nagai, Y., \& Kim, E. (2019). A New Method for Architecture Space Design Based on Substance-Field Analysis. In IOP Conference Series: Earth and Environmental Science (Vol. 233, No. 2, p. 022027). IOP Publishing.

Taura, T., \& Nagai, Y. (2012). Concept generation for design creativity: a systematized theory and methodology: Springer Science \& Business Media.

Ubarretxena-Belandia, I., \& Engelman, D. M. (2001). Helical membrane proteins: diversity of functions in the context of simple architecture. Current opinion in structural biology, 11(3), 370-376.

Venturi, R. (1977). Complexity and contradiction in architecture (Vol. 1). The Museum of modern art.

Weisberg, R. W. (2006). Creativity: Understanding Innovation in Problem Solving, Science, Invention, and the Arts. John Wiley and Sons.

Youn, H., Strumsky, D., Bettencourt, L. M., \& Lobo, J. (2015). Invention as a combinatorial process: evidence from US patents. Journal of The Royal Society Interface, 12(106), 20150272. 